\title{
Arbor
}

\section{Gabriel de Aristizábal y su viaje a Constantinopla en el año 1784}

Ricardo González Castrillo

Arbor CLXXX, 711-712 (Marzo-Abril 2005), 707-726 pp.

Estudio del manuscrito II-1051 de la Real Biblioteca de Madrid que contiene el relato de la embajada de buena voluntad enviada a Constantinopla por el monarca Carlos III en 1784, con el fin de afianzar los incipientes lazos establecidos entre España y Turquía, a raíz del Tratado de Amistad y Comercio suscrito dos años antes. La expedición, portadora de ricos presentes para el soberano otomano, estaba integrada por cuatro navios al mando de Gabriel de Aristizábal, cuya biografía se incorpora, extraída de un documento ajeno al manuscrito. La derrota seguida y las vivencias de los expedicionarios en tierras turcas, constituyen el núcleo del relato.

La Real Biblioteca de Madrid cuenta entre sus fondos manuscritos con el informe original que Gabriel de Aristizábal presentó al monarca español Carlos III al regreso del viaje que realizó a Constantinopla por mandato real, con fines de embajada. Bajo un largo título -"Extracto del Diario de la Navegacion hecha a Constantinopla en el año de 1784 por la Esquadra de S.M.Cca. al mando del Brigadier de la Real Armada Dn. Gabriel de Aristizábal, con algunas observaciones politicas del Imperio de los Turcos, según permitio su corta mansion en aquel Puerto, y Corte Otomana"-, las páginas del manuscrito, signado como II-1051 en la ordenación de la Biblioteca, incluyen el relato de aquel viaje que fue la primera misión diplomática enviada por el citado monarca español a la $\mathrm{Su}$ - 
blime Puerta Otomana, con el propósito de estrechar los incipientes lazos establecidos entre ambas Cortes a raíz del Tratado de Amistad y Comercio suscrito dos años antes, en septiembre de $1782^{1}$. Testimoniar al sultán turco los buenos deseos del monarca español a la vez que hacerle entrega, en su nombre, de unos valiosos presentes era, pues, el cometido de la flotilla de tres naves -a la que se añadió luego una cuarta- que, al mando de don Gabriel de Aristizábal y Espinosa partía del puerto de Cartagena el 24 de abril de 1784 rumbo a Constantinopla, adonde llegaría el 10 de septiembre del mismo año, después de una larga travesía no exenta de incidentes.

Consta el manuscrito de cuarenta y cinco folios de texto, de buen papel tamaño $37 \times 53 \mathrm{~cm}$., escritos a razón de 33 líneas por plana con letra de la época, de una sola mano y excelente factura, numerados correlativamente a lápiz en fecha reciente. Y lo que es más digno de resaltar por su singularidad y belleza: incluye además cuarenta y siete dibujos de extraordinaria perfección y finura de trazos, algunos de los cuales por su gran formato, se extienden sobre hojas plegadas. Hechos a pluma y coloreados a la acuarela en su mayor parte, llevan muchos de ellos la firma del artista que los realizó. En tales dibujos quedan reflejadas diversas escalas de la derrota seguida por la expedición -Malta, Siracusa y el paso de los Dardanelos, entre otras-, así como los más importantes monumentos históricos de Constantinopla -Santa Sofía, Hipódromo, los tres Obeliscos-, y la perspectiva de la ciudad desde diferentes ángulos -monte Escútari, Pera, etc.-, con una panorámica de los tres castillos que guardan la entrada del Canal. Y junto a estos dibujos de carácter toponímico, otros vienen a ser el testimonio gráfico de experiencias vividas durante la travesía -el reflotamiento de una de las naves que encalló en el paso de los Dardanelos-, o informan acerca de cuestiones que, obviamente, habían de atraer la atención de los expedicionarios, como las fortificaciones otomanas del Danubio, las piezas de artillería utilizadas por el ejército turco, los diferentes tipos de barcos de su armada y el mecanismo de transporte que empleaban para conducirlos a las atarazanas, el arsenal de Constantinopla o el sistema de abastecimiento de agua a la ciudad mediante un acueducto que arrancaba de Burgas, etc. ${ }^{2}$

Por lo que respecta al texto, incluye claramente diferenciadas las dos partes que se anuncian en el epígrafe inicial del manuscrito: el diario de la navegación en sí, y la información sobre el imperio turco. Con minucioso detalle se relata, dentro del primer apartado, la ruta seguida, mediciones realizadas y lugares visitados, así como las incidencias surgidas durante el viaje. $\mathrm{Y}$ conviene señalar que algunos de los lugares recorri- 
Gabriel de Aristizábal y su viaje a Constantinopla...

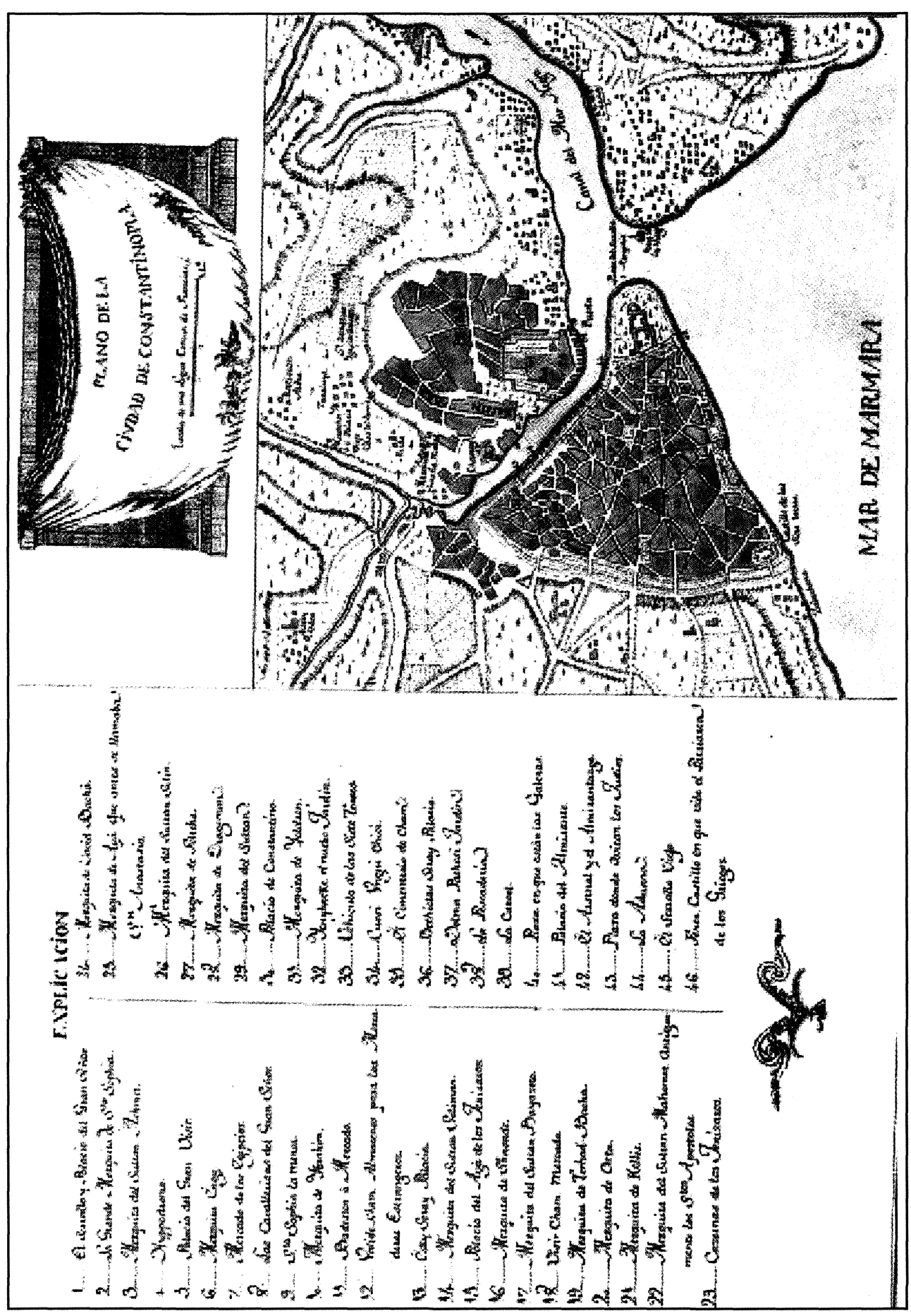


dos por los expedicionarios durante la travesía eran totalmente desconocidos para ellos, ya que los marinos españoles hacía mucho tiempo que no los frecuentaban. Concretamente, en palabras del propio Aristizábal, desde «el tiempo de las Cruzadas, pues es la última ocasión en que la guerra llevó nuestras banderas a esta parte... y jamás había ocurrido el ir de paz hasta ahora". Tal era el caso del Archipiélago del Egeo y también del Helesponto. De ahí que hubieran de contratar los servicios de expertos navegantes, conocedores de la zona, para cubrir dichas etapas. No obstante, los expedicionarios supieron sacar provecho de estas nuevas experiencias, y, en función de sus propias observaciones, procedieron a rectificar bastantes de los datos erróneos y mediciones equivocadas que figuraban en las cartas y documentos que manejaban. Varios son los pasajes del manuscrito donde quedan consignadas tan oportunas correcciones.

La segunda parte del texto contiene multitud de noticias sobre Constantinopla, con información acerca de su clima y de sus monumentos, así como toda suerte de detalles relativos a las costumbres y forma de vida de sus habitantes, en los más variados aspectos. Tales noticias no son sino el fruto de unas vivencias y el resultado de unas observaciones personales y directas: las de aquel grupo de españoles que, en cumplimiento de su misión, permanecieron en la capital otomana más de cuarenta días -43 exactamente-, durante los cuales se mostraron siempre interesados en captar la realidad de un país que por fuerza había de resultarles exótico y diferente. Es por ello que la información recogida en las páginas del manuscrito conforman, en verdad, todo un completo cuadro socio-político-religioso de la Constantinopla de finales del siglo XVIII ${ }^{3}$.

Ahora bien, pese a la importancia de este viaje, la figura del jefe de la expedición, Gabriel de Aristizábal, no resulta fácil de perfilar ya que, sorprendentemente, son muy pocos los tratadistas que se han ocupado de su persona. Para ser exactos, apenas contamos con otros datos biográficos que los recogidos por el abogado José María de Antequera en un breve estudio, escrito en tono apasionado y con el estilo ampuloso propio de la época, conservado en unas hojas mecanografiadas ${ }^{4}$.

Se dice en él que Gabriel de Aristizábal y Espinosa nació en Madrid el 25 de marzo de 1743 y que era hijo de don Nicolás de Aristizábal, caballero de la Orden de Santiago, y de doña Rosa Espinosa, quienes se preocuparon con todo cuidado de la formación del muchacho y encauzaron su vocación hacia la carrera de las armas. En este camino, a los 17 años ingresó como guardiamarina en la Real Academia Naval de Cádiz, donde «sobresalió entre sus compañeros por su aplicación y talento», afirma Antequera, 
destacando de modo especial en el estudio de las Matemáticas y de las lenguas antiguas y modernas, de las cuales «aprendió con perfección el latín, italiano, inglés y francés». Acabada su instrucción teórica en la Academia, inició la práctica marinera navegando durante cinco años en diferentes barcos por la ruta de las Azores y de las Filipinas e intervino en algunas acciones de guerra contra los ingleses. De regreso a España, era promovido a Alférez de fragata en febrero de 1766, y poco más de un año después ascendía un nuevo peldaño en su carrera al obtener el grado de Alférez de navío, siendo destinado al Departamento de Cartagena. Dos años permaneció Aristizábal en esta ciudad dedicado a ampliar los conocimientos teóricos de su profesión mediante el estudio, al cabo de los cuales recibió la orden de embarcar en la fragata Astrea que partía hacia Manila.

Al llegar a esta capital el 9 de agosto de 1770, después de una accidentada travesía, supo de su ascenso a Teniente de fragata, efectivo desde el 18 de diciembre del año anterior. Su estancia en Filipinas comenzó con buen pie ya que apenas transcurrido un mes de su llegada, el Gobernador y Capitán General de aquellas Islas le designó para el importante cargo de Comandante del arsenal y ribera del puerto de Cavite. Y al año siguiente, el mismo Gobernador le encomendaba nuevas tareas aún más relevantes al nombrarle Comandante General de Marina de las Islas Filipinas. Como señala José María de Antequera, no deja de sorprender que la elección para puesto tan destacado recayese en un joven de la edad de Aristizábal, que contaba por aquel entonces sólo 28 años. Ello contrastaba, evidentemente, con todo el sentir de la época, inclinada a primar la veteranía y la experiencia sobre la juventud ${ }^{5}$. Quizá pudieron influir en el ánimo del Gobernador la eficacia y celo demostrados por Aristizábal en el desempeño de la primera misión que le encomendó, así como el conocimiento que poseía de aquellos territorios, adquirido en su etapa de guardiamarina. En cualquier caso, el nuevo Comandante General no defraudó la confianza puesta en él. Antes bien, en su nuevo cargo se comportó siempre como experimentado marino y también como un excelente administrador. Durante su mandato, y por iniciativa suya, se realizaron importantes obras de construcción de interés naval, a la vez que dedicaba todo su esfuerzo a la lucha contra los piratas que infestaban aquellos mares quebrantando seriamente el comercio y la navegación. El éxito le acompañó en esta empresa y fueron muchos y señalados los triunfos que obtuvo en los tres años que estuvo al frente de la Comandancia de Marina de las Filipinas.

Ascendido a Teniente de navío en 1774 , el mismo año en que murió su madre, regresó a España con la aureola de la buena gestión realizada 


\section{Ricardo González Castrillo}

en la lejana colonia. Varios hombres de Estado, llevados de su fama, solicitaron de él noticias acerca de la situación en las Islas, pidiéndole parecer sobre las reformas que precisaba la gobernación de las mismas tanto en el aspecto militar como en el puramente administrativo, cuestiones éstas abordadas por Aristizábal en una extensa memoria que escribió por entonces, la cual obraba en poder de sus descendientes por el tiempo en que Antequera redactaba la biografía del personaje. Luego de residir dos años en el Departamento de El Ferrol adonde fue destinado, a partir de 1776 «su carrera activa siguió ya esa marcha rápida que no podía por menos de seguir, atendida la grande reputación que había adquirido», en palabras de Antequera. En efecto, de 1776 a 1782 obtiene los ascensos sucesivos de Capitán de fragata (febrero 1776), Capitán de navío (mayo 1778), y Brigadier de la Armada (diciembre 1782), año este último de especial significado para las armas españolas que lograban recuperar la isla de Menorca para la Corona de España, poniendo fin con ello a un largo periodo de 74 años de soberanía británica.

Pero sin duda alguna, el 31 de agosto de 1783, fecha de su designación como Comandante de la primera embajada que el rey Carlos III enviaba al sultán turco, marca el punto culminante de la carrera profesional de Aristizábal. Muchos de los honores y distinciones que alcanzaría luego del monarca Carlos III serían la consecuencia lógica del éxito obtenido en esta misión. El más inmediato, el nombramiento de Jefe de escuadra el 14 de junio de 1785 . Y muerto este soberano, Aristizábal siguió prestando nuevos y señalados servicios a su hijo y sucesor Carlos IV y a la Marina española. Ascendido a Teniente General en 1791, dos años más tarde se le encomendaba el mando de una escuadra destinada a América con la misión especial de salvaguardar el comercio español en aquellas latitudes y prestar escolta y protección a los barcos que transportaban a la metrópoli remesas de fondos y mercaderías, los cuales eran hostilizados de continuo por corsarios afincados en la isla de Santo Domingo, en la parte sometida al dominio francés. Aristizábal cumplió su misión de proteger a los convoyes, al tiempo que emprendía una victoriosa acción de guerra contra el enclave francés de Fuerte-Delfín, en la isla de Santo Domingo, que se rindió a él por capitulación haciéndole entrega de gran cantidad de piezas de artillería y munición. La noticia de esta victoria incruenta tuvo amplia repercusión y produjo un doble efecto, psicológico y político. La Gaceta de Madrid, en su número del 1 de abril de 1794, recogía los pormenores de la misma, mientras el monarca honraba al hombre que la había hecho posible con la distinción de «Gentilhombre de Cámara con entrada". 
La vida de Aristizábal tocaba a su fin cuando en 1800 regresó de su misión americana. Pero en los cinco años que mediaron hasta su muerte todavía tendría ocasión de subir el último escalón de su carrera militar al ser nombrado Capitán General del Departamento Marítimo de Cádiz en 1802. Tres años después, a los 62 de edad, moría en la Isla de León el 5 de junio de 1805, dejando tras de sí un largo historial de servicios prestados a la Marina y a España durante los 45 años que duró su actividad profesional. Por suerte para él la muerte le libró de conocer el gran desastre que la Armada española sufriría en Trafalgar sólo cuatro meses después.

Junto a los datos esencialmente cronológicos que José María de Antequera recoge en la biografía de este ilustre marino, apunta también otros varios relativos a su carácter y personalidad que permiten bosquejar su semblanza humana. Resalta «el ánimo esforzado y sereno de este distinguido Jefe» y su condición de "hombre profundamente religioso: usando de sus triunfos con clemente benignidad, sufría sus desgracias con resignación cristiana». Señala asimismo "el espíritu de estudiosa investigación que le guiaba en todas sus empresas y viajes» y sintetiza, finalmente, todos sus panegíricos definiéndole como «uno de esos hombres llenos de valor, de lealtad y de acrisolada honradez... modelo de finura y de distinguidas maneras; una persona dulce y afable en su trato, y bondadoso para cuantos le rodeaban y estaban a sus órdenes, y más aun para los desgraciados, cuyas miserias se complacía en socorrer».

Adornado con tantas y tan nobles virtudes que venían a añadirse a una competencia profesional acreditada, no era extraño que Carlos III pensara en Aristizábal como jefe de la misión diplomática que deseaba enviar a la Sublime Puerta, tras de la firma del Tratado de Paz con Turquía suscrito el 14 de septiembre de 1782 . En consecuencia, «determinó S.M. se procediese a la remisión de los regalos que las demás naciones han acostumbrado enviar en casos semejantes a la Puerta Otomana, para sellar el pacto y estrechar los vínculos de la amistad con esta nación». Con tales palabras refleja nuestro marino el uso generalizado de los regalos en las relaciones de otros países con la Sublime Puerta, como culminación de pactos y alianzas. Y consciente Carlos III de que los regalos «son emblema del poder que los remite», puso gran cuidado en la elección de los que proyectaba enviar al sultán otomano. Pero el monarca español estaba persuadido, además, de que los turcos habrían de juzgar la valía y el poder de nuestra nación a través, precisamente, de la misión diplomática encargada de transportar y hacer entrega de los ricos presentes, y de la suntuosidad y prestancia que la rodeasen. De ahí que 
procurara con todo empeño equipar adecuadamente la escuadra destinada a Constantinopla, "sin perdonar gastos ni escasear lucimiento», a fin de que pudiera causar la favorable impresión que se pretendía.

El 31 de agosto de 1783 confiaba el monarca el mando de la misma al Brigadier don Gabriel de Aristizábal quien tomaba posesión de su cargo en Cartagena el 2 de octubre de ese año. Mientras, proseguían los preparativos de la escuadra inicialmente compuesta por tres unidades: los navíos Triunfante y San Pascual, de 80 y 70 cañones, y el bergantín Infante que contaba 18 cañones, a los que se unió más tarde -el 5 de mayo de 1784- una cuarta unidad, la fragata Santa Clotilde, de 26 cañones, una vez iniciado el viaje cuando avistaban la isla de Menorca. El Triunfante poseía una tripulación de 657 hombres y el San Pascual 556, en tanto que la fragata Santa Clotilde llevaba a bordo 231 y el bergantín Infante 121. En consecuencia, pues, sumaban 1.565 hombres. Todo el despliegue de hombres y barcos que supuso la embajada venía justificado por el deseo de proyectar ante la Sublime Puerta la imagen de España como potencia naval y nación fuerte. Pero, marginalmente, tuvo también un aprovechamiento secundario en cuanto aquélla sirvió de medio de transporte para dos tíos del emperador de Marruecos en su desplazamiento a Constantinopla, los cuales viajaban acompañados de su correspondiente séquito y bagajes, amén de un caudal de cien mil doblones de su propiedad. Asimismo figuraban a bordo los miembros de la familia del enviado extraordinario de España en la Corte Otomana. Los preparativos de la escuadra quedaban concluidos a finales de marzo de 1784 , de forma que en los primeros días del siguiente mes los barcos se hallaban ya listos para zarpar. Los navíos Triunfante y San Pascual, y el bergantín Infante, se hacían a la vela en la mañana del 24 iniciando así, "a favor del viento terral», la expedición a Constantinopla.

Tras de navegar por aguas de las Baleares y de Cerdeña, y después de una estancia de varios días en el puerto de Augusta, en Sicilia, la escuadra puso rumbo al Archipiélago griego. Pero a tres leguas de la isla de Lemnos, encalló de proa el San Pascual en un banco de arena y los marinos españoles tardaron treinta horas en reflotar la nave. Solucionado con éxito el incidente, llegó la expedición a Tenedos -la actual isla de Bozca Ada-, buscando allí la seguridad de un refugio donde aguardar el momento propicio para adentrarse en el Canal de los Dardanelos, la etapa más difícil y peligrosa de toda la travesía. Cuando al fin entró en él, quedó sorprendido Aristizábal por la costumbre turca de disparar balas reales y no simples salvas de saludo, desde las fortalezas situadas a ambas orillas. Como era lógico, el Jefe de la expedición no desaprovechó la 
Gabriel de Aristizábal y su viaje a Constantinopla...

ocasión de anotar las características más notables de las fortalezas que encontró a su paso, tanto las situadas a la entrada del Estrecho -una en la orilla europea y otra en la asiática-, como las que había de más antiguo en los Dardanelos. Y, además, dejó constancia gráfica de las mismas en sendos dibujos precisando, en la letra de los mismos, cuál era la colocación de las piezas de artillería y hasta el tipo de balas que arrojaban. Una nueva avería del San Pascual obligó a detenerse la escuadra durante varios días hasta que fue reparada. Finalmente, el 10 de septiembre fondeaban los barcos españoles en la bahía de Ceras, última etapa de su viaje, aunque sin hacer las acostumbradas salvas de saludo ni toque de campanas por haberlo solicitado así la Sublime Puerta, ya que el estrépito asustaba a la sultana, que se hallaba embarazada.

La contemplación de cuantas maravillas ofrecía Constantinopla a los ojos de los expedicionarios españoles debió marcar su ánimo con la impronta de una auténtica fascinación. Y es que, entonces como hoy, esta ciudad produce en el viajero una sensación difícilmente traducible en palabras. Aristizábal y sus hombres debieron quedar impresionados por la belleza del paisaje, si bien parece que no tanto por la de los edificios. Sus palabras reflejan tal sentimiento: «...lo delicioso de su terreno no tiene comparación. Descúbrense largas distancias en que, por un lado, hace horizonte el mar y, por otro, hay dilatados campos y llanuras, interrumpidas de algunas montañas, que presentan una perspectiva deliciosa. La más agradable que puede imaginarse es la que ofrece el Bósforo, pobladas todas sus orillas de casas (algunas muy buenas), de árboles y jardines. A la verdad, no puede mejorarse su situación. Y si concurriera con la naturaleza el arte, construyéndose los edificios según las reglas de buena arquitectura, en que son sumamente ignorantes y descuidados los turcos, resultaría un todo admirable».

Durante los casi treinta días que mediaron entre la llegada de la escuadra a Constatinopla y el momento de la recepción solemne ofrecida por el sultán otomano, Aristizábal y sus hombres desarrollaron todo un apretado programa de actividades de diversa índole. Las de carácter diplomático ocuparon buena parte de ese tiempo. Y era lógico que así fuese, pues no en balde el viaje tenía la consideración de embajada de buena voluntad, destinada a afianzar los lazos de unión con el Imperio turco. Pero a sugerencia del Enviado español, comenzó Aristizábal su actividad diplomática contactando primeramente con los embajadores extranjeros acreditados en la capital turca. Acompañado de sus oficiales acudió a cumplimentarles y su gesto fue correspondido por aquéllos con visitas a la escuadra sucediéndose, al propio tiempo, un intercambio recíproco de invitaciones a banquetes y recepciones. 


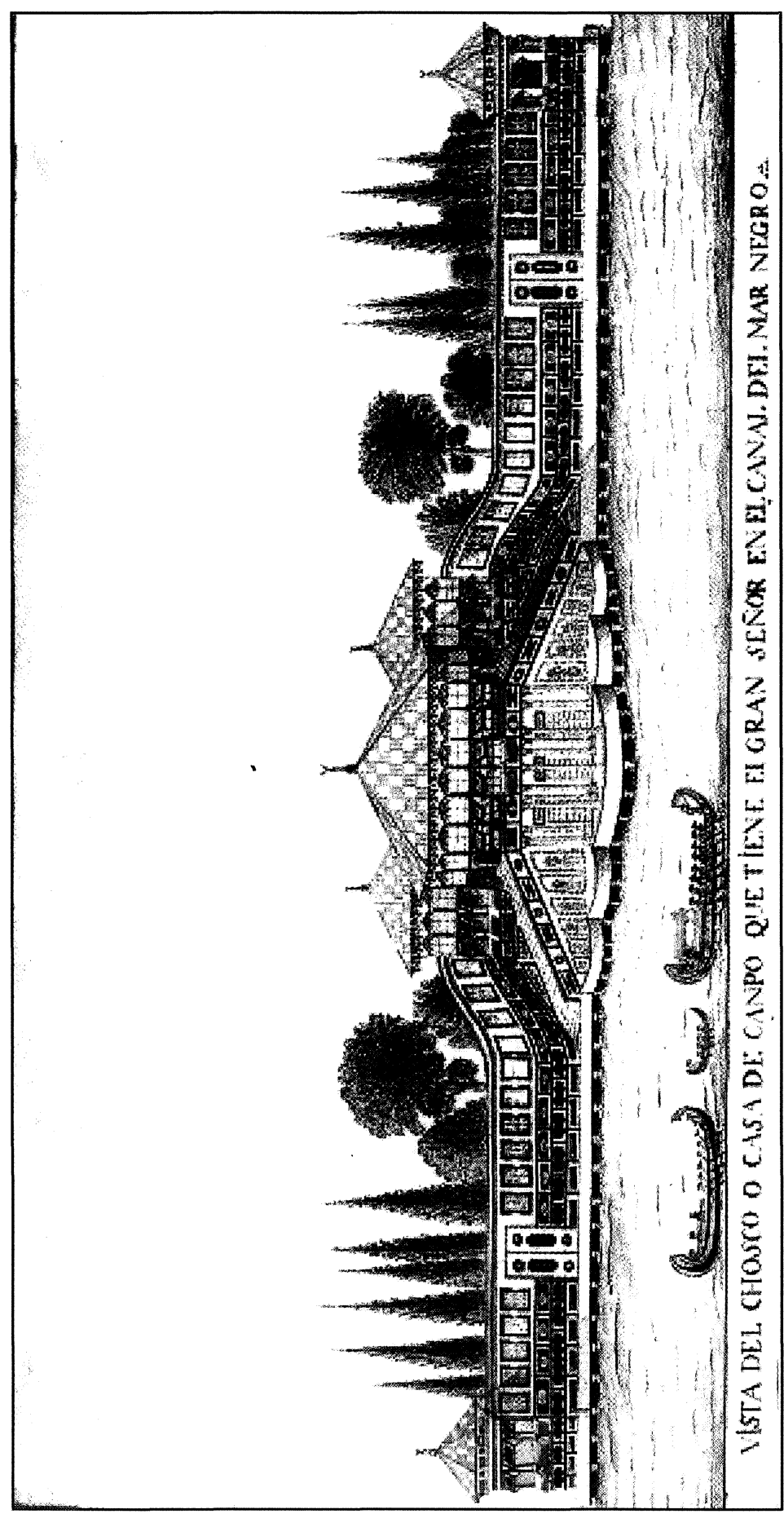


Gabriel de Aristizábal y su viaje a Constantinopla...

Del lado otomano, los marinos españoles supieron granjearse asimismo la simpatía de este pueblo por su gallardía y disciplina y también, por qué no decirlo, por su prodigalidad, unido todo ello a la buena imagen que desprendían los barcos de la flota. "A pesar de la indiferencia con que todo lo miran los turcos», apunta Aristizábal, fueron varios los personajes notables que acudieron a ver de cerca la escuadra y quedaron gratamente impresionados ante el aspecto de la misma. Y hasta el propio visir, el dignatario más influyente de la Corte, "empeñado en dar a entender el aprecio que merecían a su soberano y a él mismo las armas españolas», tuvo la deferencia de invitar al Comandante general al real sitio de Aguas Dulces.

Los días fueron transcurriendo para los expedicionarios españoles entre la asistencia a los actos sociales referidos y el interés por adquirir un conocimiento profundo y amplio del país que visitaban. Las costumbres de sus gentes, la economía, su sistema defensivo, la política, eran cuestiones todas que atraían la atención de nuestros compatriotas y a las que dedicaban buena parte de su tiempo, observando e indagando. Y por fin llegó el día culminante, la audiencia del sultán, en la fecha del 6 de octubre. Los regalos traídos desde España, tan cuidadosamente seleccionados por el monarca Carlos III, habían sido desembarcados hacía tiempo y permanecían depositados en tierra, a la espera de ser entregados al soberano otomano. Aparte de ofrecerle la liberación de cuatro arraeces y de sesenta esclavos turcos, los barcos españoles llevaron hasta Constantinopla "16 cajones con chocolate labrado, 24 fardos con cacao, 4 cajones con quina, 4 con tabaco de polvo habano, 1 con una pequeña vajilla de oro, 4 con una vajilla de plata, 13 con varias piezas de tisú de oro y plata, 21 con distintas piezas de paños exquisitos y algunas de lana de vicuña, 1 magnífica tienda de campañan. Todos estos regalos procedentes de España se incrementaron luego con otros adquiridos en la propia Constantinopla, consistentes en valiosas alhajas y objetos de uso personal recamados de pedrería.

Llegados a este punto, una cosa sorprende en la lectura del manuscrito. Y es el silencio que guarda Aristizábal acerca de su entrevista con el sultán. Ninguna palabra escribe a este respecto, extraña actitud tratándose del momento culminante de su misión. Quizá la explicación de este silencio pudiera hallarse en el desagrado que debió producirle toda la parafernalia que rodeó la audiencia, si se desarrolló -como es de suponer-conforme al ceremonial acostumbrado para esta clase de actos en la Corte otomana. El mismo Aristizábal describe con amplitud cuál era este ceremonial bastante más adelante, en la segunda parte del ma- 
nuscrito, aunque trate el tema en términos generales y no intente reflejar su propia experiencia personal. Sus palabras revelan en este punto verdadera indignación ante la serie de humillaciones a que se veía sometido cualquier embajador extranjero que acudía a la presencia del sultán, como forma de resaltar, por contraste, la personalidad de éste. Sin duda alguna el marino español debió sufrir también esas mismas vejaciones en su audiencia con el sultán, víctima, al igual que los demás embajadores, de ese ceremonial degradante que describe con acritud e indignación. Pero lo hace no como protagonista sino como pudiera describirlo un espectador cualquiera, hablando siempre en tercera persona: "se envían los regalos de la Puerta el día antes de la audiencia y se cita, en todo tiempo, al ministro extranjero para antes de amanecer. Pasa con su acompañamiento de Pera a Constantinopla y aguarda en un cuarto humilde al Introductor de Embajadores».

Cumplida la misión que les había llevado a tierras otomanas con la entrega de regalos y la entrevista concedida por el sultán el 6 de octubre, los expedicionarios españoles permanecieron en la capital turca algún tiempo más, hasta el 24 del mismo mes, dedicados a ultimar sus investigaciones sobre aquel país. Y toda la información relativa al Imperio turco y las costumbres de sus gentes que pudieron recoger en los 43 días que duró, en total, su estancia en Constantinopla es lo que constituye el interesante corpus de variopintos datos que conforman las «Noticias de la capital de Turquía", segunda parte del manuscrito. De sus monumentos, el emisario español centra su atención en describir los que él pudo ver, aquéllos que adornaban la ciudad de su tiempo. Y comienza por el Serrallo o Palacio del sultán, ubicado en la Punta del mismo nombre. El terreno que ocupaba este palacio, con sus jardines era enorme, y en las zonas destinadas al uso privado del soberano, destacaba claramente «la opulencia y suntuosidad, pero sin gusto ni lucimiento». El emplazamiento del palacio, en la parte más alta de la ciudad, permitía al sultán disfrutar de una vista inigualable en la que se alternaban el espacioso prado de Calcedonia con las montañas de Asia, cubiertas de arboleda, o las siluetas de la iglesia de Santa Sofía y del Hipódromo, mientras podía contemplar, al propio tiempo, el incesante ir y venir de los barcos por el Bósforo y, más en la lejanía, los extensos campos de la Tracia. En este entorno de incomparable belleza vivía el sultán otomano "en cuanto lujo es imaginable» y "sin fatigarle las riendas del gobierno, cedidas a sus ministros», dedicado sólo a disfrutar de sus esclavas georgianas y circasianas.

La mezquita de Santa Sofía, el Hipódromo y sus monumentos, el templo que Justiniano erigió en honor de san Baco, la Cisterna, los obeliscos 
Gabriel de Aristizábal y su viaje a Constantinopla...

de los emperadores Constantino y Marciano, la iglesia de los Santos Apóstoles, fueron otros de los monumentos que los españoles recorrieron durante su permanencia en Constantinopla y de los que dejaron constancia gráfica en dibujos realizados por orden de Aristizábal junto a las descripciones literarias de los mismos. Si los edificios antiguos de época bizantina despertaron la admiración de Aristizábal, no ocurrió igual con los de época otomana, excepción hecha de las principales mezquitas. La arquitectura otomana, evidentemente, no agradó al marino español. «La falta de gusto en la Arquitectura -afirma- priva a esa ciudad de nobles edificios que la hermoseen, porque ni las obras públicas ni las casas de los poderosos, aunque grandes, guardan proporción ni concilian el gusto".

En sus paseos por la ciudad, los españoles recorrieron las calles que, «por lo general, ni son anchas ni derechas», y visitaron el zoco o mercado, cuyo tamaño -aunque no pudieron medirlo con exactitud- «no es, al parecer, menor de un cuarto de legua y la mitad de ancho. Todo este edificio es de mampostería y techado de bóveda, para disminuir el peligro de fuego de que no se ha eximido alguna vez». Las tiendas de los artesanos dedicados a la comercialización de un mismo artículo se hallaban agrupadas en él por calles, a la manera de nuestros gremios, algunas de las cuales eran «de regular anchura y bastante claridad, pero otras son muy angostas y oscuras». Ahora bien, lo que mayormente sorprendió a los españoles fue la extraordinaria abundancia de toda clase de productos, reveladora de un gran consumo. Dentro de la especialización que presidía la organización del mercado, las calles de los plateros atrajeron de forma notable la atención de los viajeros por la riqueza ostentosa de sus tiendas, repletas de joyas engarzadas de pedrería. Los comerciantes disponían de pequeños almacenes o depósitos en unos edificios llamados $h a$ nes (jãnãt), construidos sólidamente en piedra, con puertas y ventanas de hierro, donde guardaban, bajo llave, sus mercaderías y dinero. Tales edificios contaban con la protección del gobierno, interesado en estimular la actividad comercial y que, de hecho, los defendió más de una vez «con tropa, a costa de muchas vidas, cuando el populacho sublevado ha querido asaltarlos".

Uno de los temas tratados por Aristizábal con mayor amplitud es el referente a la vivienda. Bien es cierto que centra su interés en las grandes mansiones, pertenecientes a individuos de un estrato social elevado. Característicos de esas casas privadas eran los «miradores que llaman chiuskos», provistos de tarimas bajas alrededor, que cubrían con ricas telas y cojines, bordados a veces con perlas y piedras finas. En estos quioscos hacían los señores gran parte de la vida ordinaria: recibían las visi- 
tas, tomaban café y fumaban tabaco en pipas persas o turcas, «y como la rinconada ofrece más comodidad, es entre ellos el puesto de preferencia». Las casas grandes acostumbraban a tener las habitaciones privadas en la planta superior, a un lado las de los hombres y a otro las de las mujeres, comunicados ambos sectores por un estrecho pasadizo que sólo podían franquear el señor de la casa o los eunucos, individuos estos últimos sobre quienes vierte el marino español su desprecio tachándoles de «miserables ministros de la desconfianza, indignos de contarse entre los hombres». En la zona de las mujeres, llamada harén (haram), vivían éstas una especie de 'reclusión dorada' ya que el amo «nada economiza para el mayor lucimiento de su harén y para el personal de sus mujeres y esclavas favorecidas, intentando deslumbrar la opresión con la magnificencia». El harén era, pues, un claro exponente de la riqueza de su propietario.

En ninguna casa de prestancia podían faltar los baños, «revestidos de mármol, con su estufa oculta", situados en la zona de los hombres y, normalmente, utilizados sólo por éstos. Como excepción, los había también en los harenes de los palacios de las sultanas y de algunos potentados. Pero lo habitual era que las mujeres acudieran a los baños públicos de la ciudad «que son de piedra, muy cómodos, en figura ovalada, con muchas claraboyas en el techo cubiertas de bombas de cristal». Solían bañarse allí desnudas por completo o vestidas con alguna prenda muy fina y ligera, atendidas en todo momento por sus esclavas, $y$ «pasan del baño frío al caliente sin resfriarse".

Tocado incidentalmente el tema de la mujer dentro del contexto general de la vivienda o de los baños, Aristizábal pasa luego a considerarlo de manera específica y con mayor profundidad. Y empieza anotando la ropa de vestir que utilizaban fuera de casa, puntualizando las diferencias que existían en este aspecto entre los distintos grupos étnicos o confesiones religiosas. Todas las mujeres turcas, excepto las griegas, llevaban como prenda de calle «un gabán hasta los pies, con un gran pañuelo de muselina liado a la cabeza, que las cubre y ciñe el rostro sin dejar a la vista otra cosa que los ojos». Ahora bien, en el caso de las turcas ese gabán era preferentemente de color verde o rojo, y las botas y chinelas que calzaban de tafilete amarillo, colores éstos "vedados a las que no son mahometanas». Las turcas, además, solían llevar el rostro más cubierto que las otras etnias pero, a veces, «las que saben que no son feas, suelen padecer algunos descuidos para llamar la atención, manifestando las perfecciones de su cara". Las mujeres armenias, a su vez, mostraban menos cuidado en ocultar sus facciones, mientras que las judías y las grie- 
Gabriel de Aristizábal y su viaje a Constantinopla...

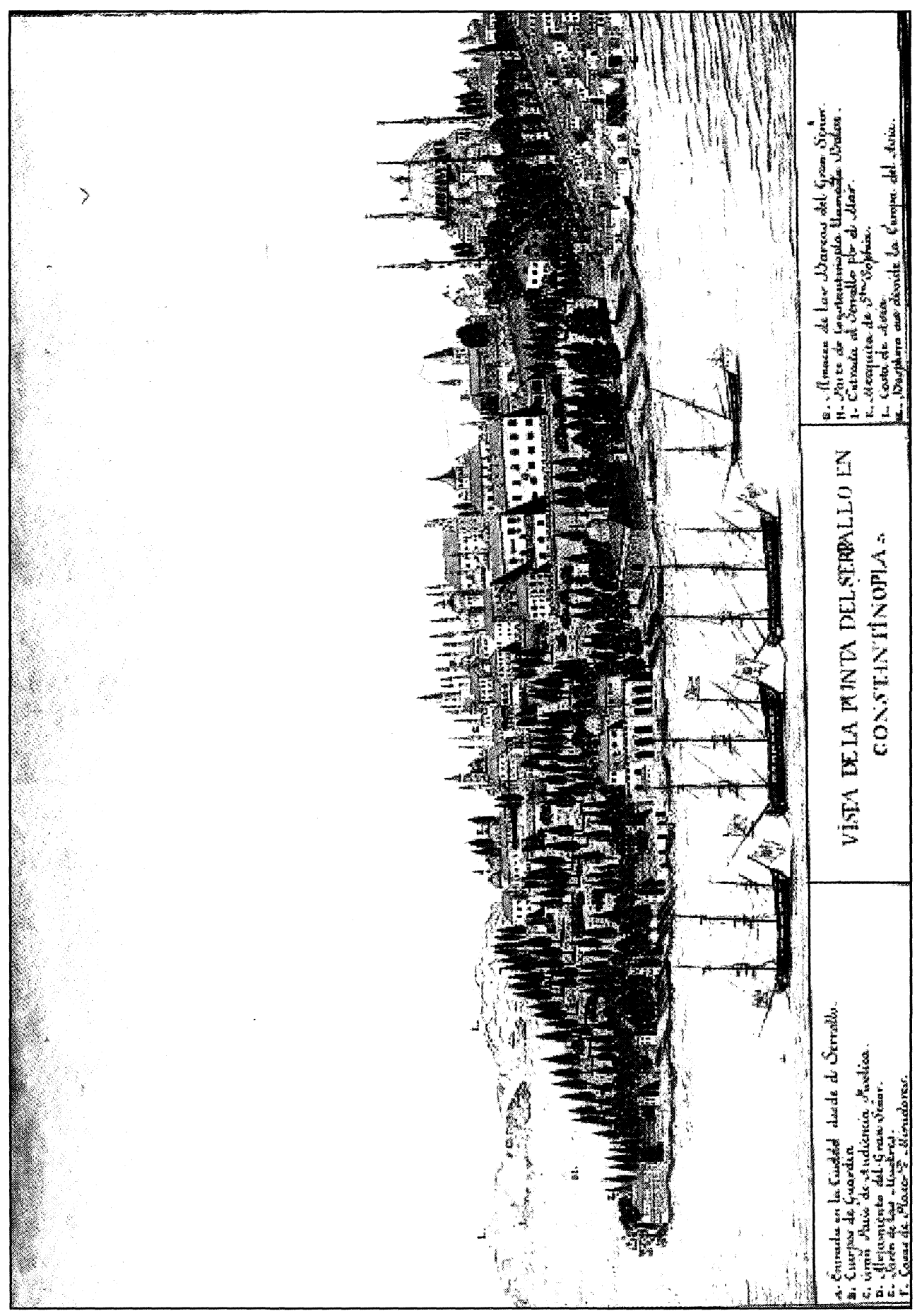


gas las llevaban descubiertas por completo. Tal indumentaria era "tan desairada como propia a disfrazar la persona y ocultarla del más celoso marido». Curiosamente, pues, Aristizábal relaciona la infidelidad conyugal de la mujer turca con su manera de vestir fuera de casa, ya que ésta contribuía a hacerla pasar desapercibida a la vigilancia del marido. Es más, apunta como algo habitual tal conducta femenina, al tiempo que señala como frecuentados lugares de citas clandestinas las tiendas de los judíos «que, siendo bien pagados, no se desdeñan de hacer [de] sus casas lupanares». Y llega a justificar las relaciones extra-matrimoniales de las mujeres, presentándolas como una forma de reaccionar contra la tiranía y opresión a que se veían sometidas por parte del marido. En realidad, las relaciones ilícitas en la sociedad otomana eran practicadas tanto por el hombre como por la mujer, pero, eso sí, dentro del más estricto sigilo y procurando siempre no dar escándalo. De suerte que, "aunque se arda la ciudad en tratos ilícitos, se oculta enteramente a la vista del público».

Una breve referencia al tipo de diversiones habituales en la sociedad otomana, masculina y femenina, cierra en el texto las páginas dedicadas a la mujer. Presenciar la danza de esclavas y bailarines o los combates de luchadores, montar a caballo y escuchar casi en silencio el murmullo del agua que corría en arroyos y surtidores, eran algunas de tales distracciones. Y es que la dulzura del clima parecía que rechazara "todo estruendo y ejercicio violento, inspirando el silencio, el sosiego, y la aversión al trabajo, como inútil, en donde vive tan de asiento la abundancia».

Aristizábal constató la profunda decadencia en que estaba sumida la Turquía otomana, antaño tan formidable, que lejos de pensar ahora en acometer "piensa sólo en defenderse». Y es que no podía hacer otra cosa. Las gentes habían perdido todo espíritu combativo y vivían dedicadas a la inactividad y al lujo, nada conocían de los nuevos adelantos en el arte militar, contaban con un ejército numeroso pero en el que había realmente pocos soldados capacitados, y, para remate, las "gentes de letras», los ulemas, mantenían una notoria rivalidad con los altos jefes militares. "Cualquiera de estas causas produciría por sí sola la pérdida de un reino» y, todas ellas juntas, habían llevado a Turquía a aquella situación de decadencia. Curiosamente, Aristizábal anima a las potencias europeas a aprovecharse de «la presente coyuntura de flojedad, desaliento y humillación en que se ven los turcos para estrecharlos a sus primeros confines", palabras bien poco diplomáticas, escritas por una persona que, aunque circunstancialmente, había actuado como embajador de buena voluntad.

Los preceptos coránicos y la Šarì ‘a (turco, Šerīat) o ley religiosa sunnī , constituían el fundamento del estado otomano y también de su ordena- 
Gabriel de Aristizábal y su viaje a Constantinopla...

miento jurídico. El estudio del texto sagrado y la interpretación de la Šeriat eran competencia de los "hombres de letras", los ulemas, quienes se habían erigido en «depositarios de la Ley y del Derecho y, como tales, gozaban de la veneración del pueblo. Hasta el propio sultán les respetaba y hacía objeto de exenciones y privilegios, como el muy señalado de poder heredar y dejar, a su vez, bienes en herencia en contra de la situación de los demás funcionarios públicos, de cuyos bienes muebles era único heredero el sultán, mientras el estado lo era de sus bienes raíces.

Lógicamente, todo lo concerniente a la milicia turca tenía que despertar de modo especial la atención de los expedicionarios españoles. Por ello no es de extrañar la abundancia de noticias que proporciona el manuscrito acerca de los distintos cuerpos del ejército y sus mandos, sistema de recluta, armamento y, en definitiva, la organización militar del Imperio otomano en aquella centuria decimoctava. La evocación del pasado era, sin embargo, inevitable tratándose de un ejército que, en otro tiempo, tuvo aterrorizado al mundo occidental. E inevitable también la comparación entre lo que fue y la realidad del presente. $\mathrm{Y}$ en este recuerdo del pasado, Aristizábal reconoce a los turcos el mérito de haber sido pioneros en la utilización de tropas regulares a imitación de los antiguos romanos, cuando en Europa se desconocía el uso de las mismas. Mención preferente dedica al cuerpo de los jenízaros, formado antaño, desde el siglo XIV, por «muchachos de los enemigos que [Murad I] sojuzgaba a su Imperio. Los hacía instruir y abrazar el mahometismo, ejercitar en las armas y acostumbrarse a los peligros». Y cuando cesaron las conquistas y faltaron aquellos soldados de procedencia foránea, su lugar fue ocupado por turcos «que conservaban, aunque no imitan hoy, la gloriosa memoria de las acciones de sus predecesores». Aristizábal apunta que «en el día habrá de ellos cien mil hombres distribuidos en las fortalezas fronterizas a los estados de Rusia y Alemania, y otros cuarenta mil de guarnición en la Capital, donde reside como gobernador de ella el agá, que es Comandante general de todo el cuerpo de jenízaros, extendiéndose su mando a las plazas y puestos que guarnece su tropa. Su segundo se titula kulquiaya». Este jefe de los jenízaros, además de percibir un sueldo elevado, disfrutaba de importantes privilegios, entre ellos la prerrogativa de ocupar la derecha del sultán en las apariciones públicas de éste.

Hasta que en el siglo XVI Jayr al-Dīn Barbarroja creó la gran flota otomana que tantos días de gloria dio al Imperio, la marina había sido el punto débil de su organización militar. Pero en la época en que escribía Aristizábal atravesaba la misma decadencia que el resto del ejército. El 
hecho de que hubiera un solo arsenal, el de Gálata, era ya, para el marino español, un claro indicio de esa debilidad, máxime teniendo en cuenta que aquel arsenal "apenas merece el nombre de tal». Los bosques de Moldavia abastecían de madera, Siberia proporcionaba hierro, y El Cairo, estopa y cáñamo, adquiriéndose en Francia y Gran Bretaña las agujas de marear y las anclas. Aristizábal cifra el total de la fuerza naval turca en 22 navíos de cincuenta a sesenta cañones, salvo uno de setenta; 14 fragatas, "desde corbetas hasta de 40 cañones»; 10 jabeques; y 9 galeras «que son de figura más regular». Ahora bien, ninguno de estos barcos pudo ver de cerca el marino español pese a haberlo intentado, y se duele de ello sin indicar el motivo. Su contemplación de los barcos fue, pues, desde lejos solamente, "al paso por el canal». Pero aun en tales circunstancias, las características que pudo apreciar en ellos no le agradaron.

Cumplida la misión y tras prolongar su estancia en Constantinopla algunos días más, los expedicionarios españoles iniciaron el viaje de regreso a España. El itinerario seguido en esta ocasión, así como las sucesivas etapas cubiertas figuran tratados en el manuscrito con mucha menor amplitud que las correspondientes al viaje de ida. El mismo Aristizábal que no escatimó entonces en detalles para describir la derrota seguida, se muestra ahora, por el contrario, conciso y escueto en sus apreciaciones. Por fin, tras de algunos contratiempos, al anochecer del día 14 conseguía la escuadra española abandonar las peligrosas aguas del Archipiélago, y lo hacía "por donde había entrado», prosiguiendo la navegación rumbo a la isla de Malta. Luego de pasar la obligada inspección sanitaria, los barcos españoles fueron autorizados a entrar en el puerto de Marsa Muschet donde fondearon el 9 de diciembre. La estancia en esta isla se prolongó más de lo necesario por haber recibido una Real Orden de Carlos III disponiendo que quedaran en Malta los barcos españoles hasta tanto no estuvieran preparadas dos galeras que habían sido adquiridas al Gran Maestre, con el fin de que realizaran juntos el viaje a España y pudieran prestar a aquéllas adecuada protección. Finalmente, toda la escuadra, incluidas las dos galeras últimamente adquiridas, se hacía a la mar el 2 de mayo y llegaba al puerto de Cartagena el 31 de mayo de 1785. Cuatro días más tarde, a bordo del navío Triunfante, el Comandante Aristizábal redactó el balance de gastos de la expedición, justificativo de los 315.000 reales de vellón que había recibido de la Real Hacienda al iniciar su viaje a Constantinopla, documento que se conserva actualmente en el Archivo Museo de Bazán.

El 7 de junio Aristizábal recibió la orden de presentarse en la Corte para informar al monarca de su viaje. Del desarrollo de esta entrevista 
apenas si conocemos algo. Pero sabemos que fue entonces cuando presentó al rey el hermoso manuscrito objeto del presente estudio. Y que, complacido el monarca con el resultado de la expedición, tuvo a bien recompensar al Comandante elevándolo a la categoría de Jefe de escuadra, y a varios de sus oficiales con distintos ascensos.

\section{Notas}

1 La apertura de relaciones diplomáticas con Turquía, tras siglos de enconadas luchas por la supremacía mundial, constituye uno de los logros más significativos de la política exterior del monarca español Carlos III. En su etapa de rey de Nápoles había ya iniciado unas primeras negociaciones con la Corte otomana y concluido con ella un Tratado de Comercio y Navegación. Y cuando en 1759 el entonces Carlos VII de Nápoles pasó a ocupar el trono de España, fue el propio sultán Mustafá III quien «entre las enhorabuenas que le significó con el motivo de su advenimiento al trono español, propuso la continuación de su alianza", como señala Aristizábal en la Introducción de su informe. Pero los acuciantes problemas que acapararon la atención de Carlos III en los momentos iniciales de su reinado fueron retrasando el acuerdo con los turcos. Ello no impidió, sin embargo, la existencia de conversaciones y contactos entre ambas partes, mantenidas «ya por varias embajadas extranjeras residentes en Constantinopla, ya por algún emisario del mismo sultán» sigue diciendo Aristizábal. Pero las negociaciones definitivas las llevó a cabo, por parte española, don Juan de Bouligny, comisionado a tal efecto con carácter extraordinario ante la Corte otomana. Y tuvieron su culminación en el deseado tratado de paz con el sultán Abd-ul-Hamid I, que fue firmado en Constantinopla el 14 de septiembre de 1782 y hecho público en España exactamente dos meses después, el 14 de noviembre. Atrás quedaban tres largos años de difícil diálogo, superado finalmente por la consideración de la mutua conveniencia que suponía el tratado para las dos potencias. Por lo que a España se refería, venía a significar la posibilidad de establecer lazos de análogo carácter con los países del Norte de África a fin de asegurar el comercio español en los puertos de Levante, tan amenazados siempre por la piratería berberisca. Vid. Artículos de Paz y Comercio Ajustados con la Puerta Otomana en Constantinopla, a 14 de septiembre de 1782, por el ministro plenipotenciario de S.M. el Sr. Don Juan de Bouligny y el de la misma Puerta, el Haggi Seid Muchemed, Baxa, Gran Visir. Madrid, Imprenta Real, 1783. Una edición posterior del tratado fue hecha cuatro años más tarde, en 1787. Vid. también SÁNCHEZ ORTEGA, M.H. (1989): Las relaciones hispano-turcas en el siglo XVIII. Hispania, 171, 151-195. Sin duda por error tipográfico, se atribuye en este artículo a Carlos IV el envío de la escuadra mandada por Aristizábal (p.183). Por otra parte, la autora no menciona el ms. de la Real Biblioteca, y quizá por desconocerlo, cita el Diario de Aristizábal con el título de «Travesía del Mediterráneo, avería del navío San Pascual, etc," (p. 184).

${ }^{2}$ El texto y dibujos del manuscrito de la Real Biblioteca han sido reproducidos en mi libro El viaje de Gabriel de Aristizábal a Constantinopla en 1784. Fundación Universitaria, Madrid, 1997.

${ }^{3} \mathrm{El}$ contenido de esta $2^{\mathrm{a}}$ parte del texto se halla recogido por un capellán de la Armada llamado Antonio de Pereira, contemporáneo de Aristizábal, en el cartapacio que 


\section{Ricardo González Castrillo}

reunió de papeles varios sobre temas militares copiados por él, el cual se encuentra en la Biblioteca Nacional de Madrid, ms. 13.871. El fragmento tomado de Aristizábal ocupa allí los ff. 33-70r y coincide, salvo ligeras variantes, con el texto del manuscrito de la Biblioteca Real. En cabeza del f. 33 figura el siguiente epígrafe: «Noticias del Imperio y Capital de Turquia, vltimamente obseruadas por el Gefe de Esquadra de la Real Armada Don Gabriel de Aristizabal, durante el tiempo que estubo fondeado con su esquadra en Constantinopla , en el Año de 1784».

4 Son 22 hojas de tamaño folio -portada y 21 de texto- insertas en el ms. 2011 del Museo Naval de Madrid, de contenido misceláneo, donde ocupan los folios 117 a 138 . Van escritas a doble espacio, sólo al recto, a razón de 27 líneas por plana. El título figura en la portada: «Don Gabriel de ARISTIZABal Teniente GeneraL». Y se repite luego al comienzo del texto, cuyas primeras líneas mencionan expresamente la impresión de este trabajo: «La presente biografía está escrita por el Sr. D. José María de Antequera, abogado del colegio de esta corte y persona muy ilustrada, que la publicó en un folleto impreso en Madrid en 1854».

5 «[Esta] elección apenas se concibe en una época en que la juventud militaba siempre en las últimas filas, y en que sólo la edad y los grandes servicios daban derecho a posiciones tan elevadas y honoríficas». Museo Naval, ms. 2011, f. 123. 